\title{
APPLICATION OF WEIGHT-HEIGHT RATIOS AND BODY INDICES TO JUVENILE POPULATIONS-- THE NATIONAL HEALTH EXAMINATION SURVEY DATA
}

\author{
JUDITH KILLEEN, DOUGLAS VANDERBURG and \\ WILLIAM R. HARLAN \\ Schools of Public Health and Medicine, University of Michigan, \\ Ann Arbor, MI 48109, U.S.A.
}

(Keceived in revised form 16 December 1977)

\begin{abstract}
Properties of four weight-height ratios were studed in data from the U.S. Health Examination Survey (Cycles II and III) of a national probability sample of youths aged $6-17 \mathrm{yr}$ $(N=13,867)$. These ratios (weight/height, weight $/$ height $^{2}$, weight $/$ height $^{3}$, weight $/$ body surface area) were examined for their correlation with adiposity (infrascapular skinfold thickness) and muscle mass (estimated muscle circumference) and for their relationship to selected physiologic and biochemical measurements. Weight/height ${ }^{2}$ (Quetelet's index) correlates best with skinfold thickness for all age-race-sex groups. However, weight-height ratios may be a better indicator of muscle mass than of adiposity because the ratios generally show higher correlations with muscle circumference than with skinfold thickness. Weight/body surface area (BSA index) is the ratio which shows the highest overall correlation with muscle circumference. The relationships of the ratios are different for various biochemical and physiologic parameters, and these data can be used for selection of an index appropriate to the investigative aims of the study.
\end{abstract}

Epidemiologic studies generally use height and weight as measurements of body size, but few studies measure body components, such as adipose tissue, muscle, or skeletal size, because of technical difficulties. To make estimates of these components, ratios of "body mass" are often constructed from height and weight and these ratios are related to various physiologic parameters and to disease states [1-5]. Most of these relationships have been assessed in adult populations. Weight-height ratios have not been studied extensively in representative young populations where growth and changing body composition may cause different relationships than those in adults. The United States Health Examination Surveys (Cycles II and III) provide extensive data on the growth and development of a national probability sample of youths aged 6-17 yr. These data afford a unique opportunity to examine the properties of weight-height ratios in a juvenile population.

Weight-height ratios may reflect several components of body mass. Adiposity is most commonly inferred when these ratios are employed, but muscle mass and skeletal size may also be estimated by these ratios and may be related to physiologic measurements. The process of growth and maturation is associated with rapid changes in body composition and, therefore, the relationships of these ratios may differ from adult relationships and change with age.

In this analysis, data from the Health Examination Surveys are examined from several perspectives. Firstly, the weight-height ratios are evaluated for their similarity to skinfold thickness, to estimated muscle circumference, and to height. These measurements are taken as estimates of adipose tissue, muscle, and skeletal size. This analysis permits

Requests for reprints to: William R. Harlan, M.D. G-1209 Towsley, University of Michigan Medical Center, Ann Arbor, MI 48109, U.S.A. 
inferences about which weight-height ratio relates best to particular body components. Secondly, the weight-height ratios and these body components are investigated with respect to their correlation with selected physiologic and biochemical measurements. These analyses provide a rational basis for selection of an appropriate ratio or index of body composition for use in epidemiologic studies of youths.

\section{MATERIALS AND METHODS}

\section{Populations}

Cycle II of the National Health Examination Survey (conducted between July, 1963 and December, 1965) examined a national probability sample of the non-institutionalized U.S. population aged 6-11 yr. Of those sampled, $7119(96 \%)$ were examined. Physical examination and a battery of anthropometric measurements were included in this examination. The target population in Cycle III (conducted March, 1966 to March, 1970) comprised youths aged 12-17 yr. Seven thousand five hundred and fourteen individuals were selected into this sample, and $6768(90 \%)$ were examined. In addition to a physical examination and anthropometric measurements, several blood chemistry determinations were made. Details of the sampling and examination procedures of Cycles II and III have been described $[6,7]$.

\section{Measurements}

Weight, height, and skinfold thickness were measured similarly in the two surveys $[8,9]$. Skinfolds were measured using a Lange skinfold caliper calibrated to exert a constant pressure of $10 \mathrm{~g} / \mathrm{mm}^{2}$. Infrascapular, triceps, and subscapular skinfold measurements were made in Cycle II, and in Cycle III these measurements plus the suprailiac skinfold were obtained. Infrascapular skinfold thickness was used in the present analyses because of its high responsiveness to environmental factors, low error of measurement, and high correlation with the other skinfold measurements.

An estimate of mid-arm muscle circumference (lean component) was obtained by correcting the upper arm girth for the thickness of the triceps skinfold as follows: estimated muscle circumference $(E M C)=$ upper arm girth- $\pi \times$ triceps skinfold [10]

Two supine blood pressure readings were made in Cycle II, one at the beginning and another near the conclusion of the examination. An average of these two readings was used in the analyses involving 6-11 year-old children. For the sample of 12-17 year-old youths (Cycle III) a sitting blood pressure reading obtained at the end of the physical examination was used in these analyses. The mean blood pressure and distributions for this reading are similar to levels reported by others [11], and the other pressures recorded in this survey are divergent.

Blood analyses obtained in Cycle III included hematocrit, total serum cholesterol, and serum uric acid.

\section{Analyses}

Various permutations included relative weight (weight/height), Quetelet's index (weight $/$ height $^{2}$ ), and a modification of ponderal index (weight $/$ height $^{3}$ ). An index based on body surface area* was also calculated (weight/body surface area). The index, designated here as the body surface area index (BSA index), is another means of correcting weight for height, since the formula for body surface area is based on weight and height.

Simple correlation coefficients were calculated between the four weight-height ratios and height, infrascapular skinfold thickness, estimated muscle circumference, blood pressure, and blood measurements. Log transformations of the weight/height ratios yielded essentially the same results, and therefore the results are presented for untransformed data. The large population permitted separation into age, sex, and race groups.

*Body surface area in $\mathrm{m}^{2}=(\mathrm{wt} \text { in } \mathrm{kg})^{0.425} \times(\mathrm{ht} \text { in } \mathrm{cm})^{0.725} \times 0.007184$ 


\section{RESULTS}

\section{Relationships among weight-height ratios and body components}

Skinfold thickness. Each of the weight/height ratios is significantly correlated with infrascapular skinfold thickness for each age-race-sex group (Table 1). In 15 of the 16 categories (all except black males aged 9-11), Quetelet's index (weight/height ${ }^{2}$ ) has the strongest correlation with skinfold thickness. The index with the weakest correlation is weight/height ${ }^{3}$, having the lowest coefficient in 12 of the 16 categories. With increasing age, the correlation between skinfolds and each ratio increases.

Black males have greater variability and have slightly lower correlation coefficients for each index. Otherwise, the race-sex groups show a similar overall pattern.

Height. Skinfold thickness is correlated significantly with height for all age-race-sex groups except white and black females aged 15-17 (Table 2). Estimated muscle circumference correlates significantly with height for all age-race-sex groups. The magnitude of the height correlations with skinfold thickness and muscle circumference decreases with increasing age.

The weight-height ratio that most closely approximates the relationship of skinfold thickness to height is Quetelet's index. The ratio that most closely approximates the relationship of estimated muscle circumference to height is body surface area index (BSA index).

Estimated muscle circumference. Each weight-hcight ratio and skinfold thickness correlates significantly with estimated muscle circumferences for all age-race-sex groups (Table 3). The correlation coefficients with weight-height ratios, except for weight/ height $^{3}$, are generally higher than the corresponding coefficient for skinfold thickness.

BSA index and relative weight show the highest correlation with estimated muscle circumference, with BSA index more likely to show higher correlations in age group 12-17 and the relative weight more frequently exhibiting higher correlations at ages 6-11. On the other hand, weight/height ${ }^{3}$ most closely approximates the relationship of skinfold thickness to estimated muscle circumference.

With increasing age, skinfold thickness has an increasing correlation with muscle circumference until ages 15-17, when it plateaus or decreases slightly.

\section{Relationships among body mass indices and physiologic measurements (Appendix)}

As an aid to investigators who may wish to select an appropriate index for study of juvenile populations, we selected several physiologic measurements and examined the correlations with body mass indices. These tables are presented as guides for selection of an appropriate index, and no comments are made on the physiological or clinical significance.

Blood pressure. Significant correlations for all indices were found with systolic blood pressure (Appendix, Table 1). Estimated muscle circumference tends to have higher correlations with systolic blood pressure than does skinfold thickness. Skinfold thickness and, somewhat less consistently, muscle circumference show a trend toward increasing correlation with blood pressure as age increases.

None of the weight-height ratios stand out consistently as the best approximation to the correlation with either skinfold thickness or muscle circumference for all ages. However, Quetelet's index appears to be the best approximation to the relationship with skinfold thickness for ages $6-11$, and weight/height ${ }^{3}$ for ages $12-17$. Relative weight most frequently shows the highest correlation with systolic blood pressure.

Diastolic blood pressure has higher correlations with both skinfold thickness and muscle circumference at ages 12-17 than at ages 6-11 for each race-sex group, but otherwise the trends with age are not entirely consistent (Appendix, Table 2).

Serum cholesterol. Skinfold thickness correlates significantly with serum cholesterol for all four age-sex groups in whites, although the correlations are small (Appendix, Table 3). Estimated muscle circumference is significantly correlated only in 15-17 yearold white males and females. 

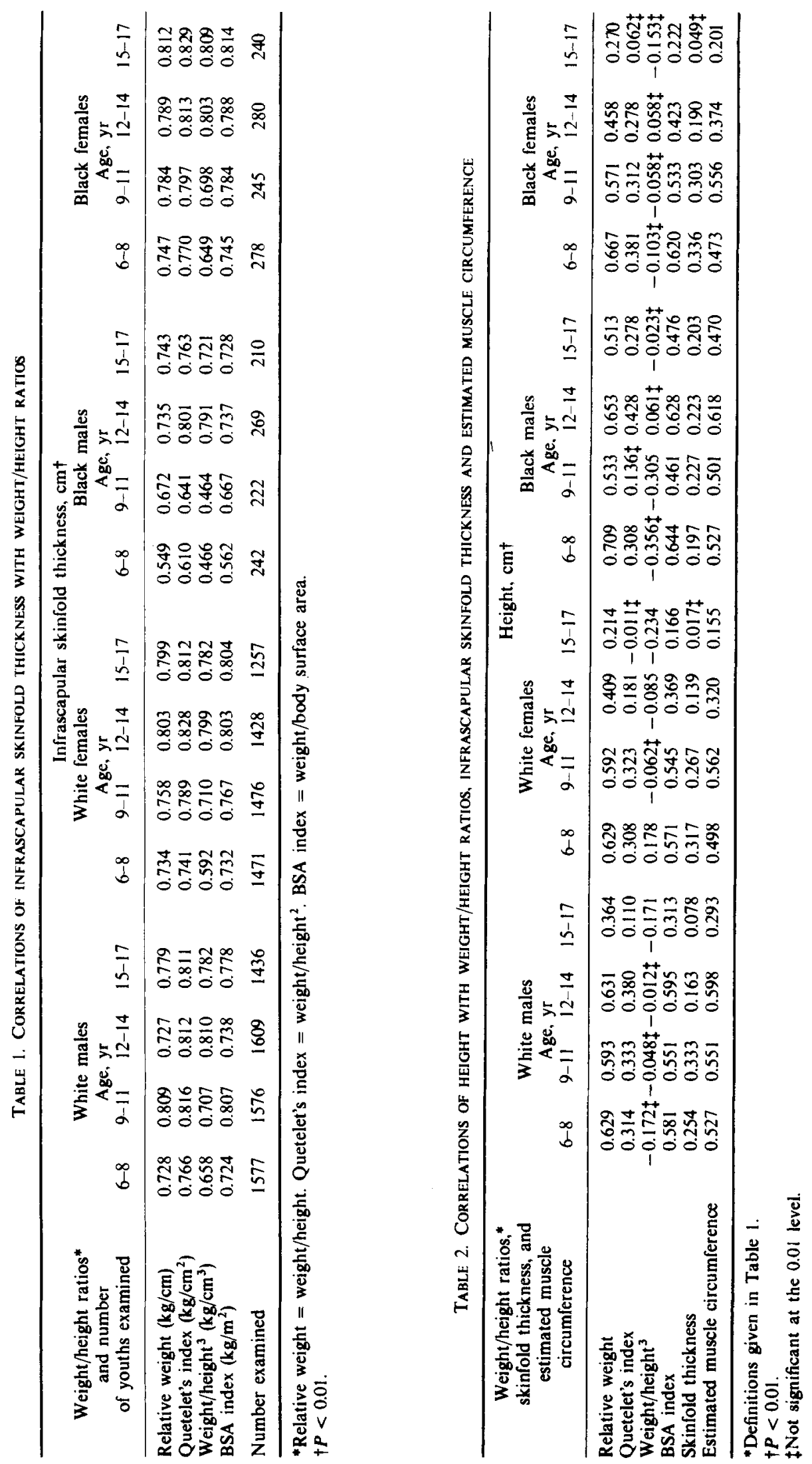


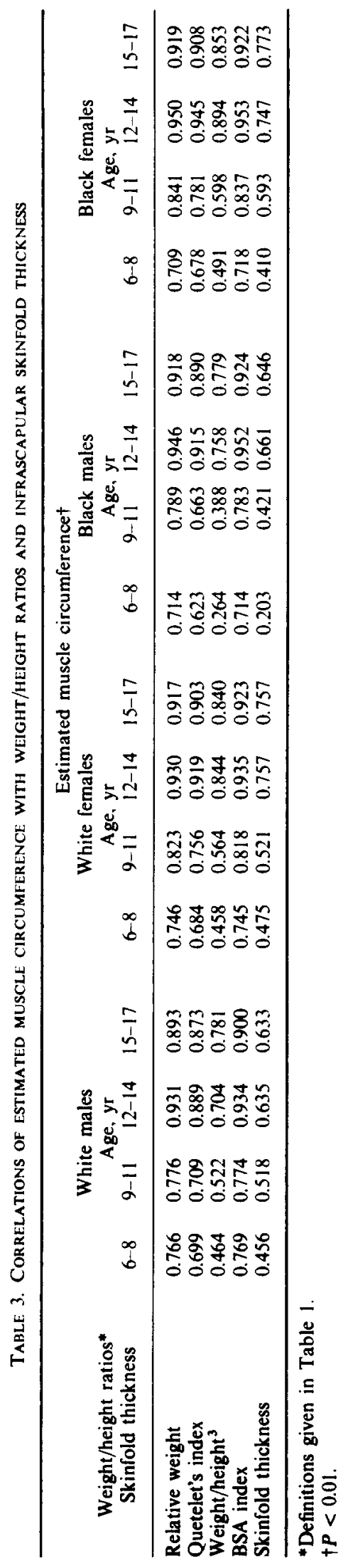


Hematocrit, Skinfold thickness and estimated muscle circumference are significantly correlated with hematocrit for all age-race-sex groups except black females and black males aged 12-14 (Appendix, Table 4). The correlation coefficients for estimated muscle circumference are higher in magnitude for males than for females. Black females show no significant correlations with respect to hematocrit for weight-height ratios, skinfold thickness, or estimated muscle circumference; while the other three race-sex groups show significant correlations in 33 of the 36 categories. The weight-height ratio that most consistently shows the highest correlation with hematocrit is relative weight, but none of the ratios display good approximations to the relationships with body components.

Serum uric acid. Significant correlations with serum uric acid were found for each body component and ratio. Weight/height ${ }^{3}$ most closely approximates the relationship of skinfold thickness to serum uric acid for all groups except black females, where Quetelet's index yields the best approximation. None of the weight/height ratios consistently approaches the correlation found for muscle circumference.

\section{DISCUSSION}

The data are presented so that the interested investigator can select the most appropriate index for a particular use, but some general comments are warranted. The data, though collected in a cross-sectional manner, may be viewed with respect to longitudinal trends. The national probability sampling, high participation rates, and standardized procedures minimize bias. In support of this concept, a subset of 2200 participants in Cycle II were reexamined 4 years later in Cycle III. The measured characteristics in this subset are indistinguishable from those of the total sample for each age-race-sex group. These considerations provide a justification for examining age trends and differences in relationships between race-sex groups.

Several studies in juvenile populations have suggested that adiposity, as measured by skinfold thickness, is related to height [12-14]. These data from the National Health Examination Survey data corroborate this finding. Skinfold thickness and height are correlated in all age sex groups except females aged 1517 . Therefore, this relationship is not independent of growth and maturation. Since skinfold thickness and height are independent in young and middle-aged adults, one would expect to see decreasing correlation between skinfold and height with age as the children reach maturity. This trend is present in Table 2. Females, who mature earlier than males, have the highest correlation cocfficients at ages $6-8$, and these coefficients decrease until they lose statistical significance at ages 15-17, when the majority are fully grown [14]. Males have the highest correlation at ages 9-11, and this decreases in each successive age group. It is likely that after age 17 , when most of the males can be expected to have completed growth, height and skinfold thickness would no longer be correlated. Similar considerations relate to estimated muscle circumference which is also correlated with height. Females again have an earlier peak in the strength of the correlation, at ages 9-11 versus $12-14$ for males, after which the coefficients show decreasing magnitude at subsequent ages.

Selection of the best weight-height ratio to estimate either adiposity or muscle mass must take into account their association with height in juvenile populations where growth confounds the relationship. Therefore, two factors must be evaluated: the correlation of the weight-height ratios with skinfold thickness and estimated muscle circumference, and the relationship of the ratios to height. For estimating adiposity, Quetelet's index (weight-height ${ }^{2}$ ) appears to satisfy both criteria better than the other ratios. Correlation coefficients as high as 0.8294 (Table 1) were found between Quetelet's index and skinfold thickness. This means that $69 \%$ of the variance of the index is accounted for by skinfold thickness. Assuming that skinfold thickness is a reliable estimate of subcutaneous fat, such a strong and highly significant correlation indicates that Quetelet's index can be used as a measure of adiposity in juvenile populations. Further, the correla- 
tions between height and Quetelet's index resemble those between height and skinfold for each age-race-sex group (Table 2).

The various weight-height ratios, although significantly correlated with skinfold thickness, are more highly correlated with estimated muscle circumference. This relationship is particularly prominent for body surface area (BSA index) and relative weight, and somewhat less so with Quetelet's index. Correlations as high as 0.9530 were found between estimated muscle circumference and BSA index, indicating that $91 \%$ of the variance of BSA index can be accounted for by muscle mass. The BSA index also most closely approximates the relationships of estimated muscle circumference to height, thus best satisfying both criteria. It appears that weight-height ratios are better indicators of muscle mass than of adiposity in juvenile populations. In growing children, the growth velocities of fat, muscle, and bone differ at various ages [14]. Adipose tissue increases from ages 8-11 and recedes as bone and muscle growth increase thereafter. The expected changes in correlations between weight-height ratios and skinfolds or muscle circumference are observed in the Health Examination Survey data for males, but not for females.

In some situations, an investigator may be more interested in a weight-height ratio that correlates best with a specific variable rather than a ratio that most closely approximates skinfold thickness or muscle circumference. In instances where correlations with one or more of the weight-height ratios are substantially higher than those with either skinfold thickness or estimated muscle circumference, the ratio may be measuring the interaction of both adiposity and muscle mass or of other components of body mass. For example, in selecting an index for use in a study involving systolic blood pressure, one may be interested in all aspects of body mass as measured by the weight-height relationship and not specifically adiposity or body mass. In this case, the index that is most highly correlated with blood pressure would be chosen, rather than the one that most closely approximates the relationship to skinfold thickness or estimated muscle circumference. To permit selection of the most useful index that might be applied in an epidemiologic study, correlations are presented in the Appendix (Tables 1-5) for selected physiologic variables.

Acknowledgements-We are indebted to Paul Leaverton, Ph.D., and Joan Cornoni-Huntley, Ph.D., for help in obtaining these data and for valuable suggestions regarding analysis.

\section{REFERENCES}

1. Benn RT: Some mathematical properties of weight-for-height indices used as measures of adiposity. Brit J Prev Soc Med 25: 42-50, 1971

2. Klein BE, Cornoni JC, Jones F, et al:: Overweight indices as correlates of coronary heart disease and blood pressure. Hum Biol 45(3): 329-340, 1973

3. Evans JG, Prior IA: Indices of obesity derived from height and weight in two Polynesian populations. Brit J Prev Soc Med 23: 56-59, 1969

4. Khosla T, Lowe CR: Indices of obesity derived from body weight and height. Brit J Prev Soc Med 21: $122-128,1967$

5. Billewicz WZ, Kemsley WF, Thomson AM: Indices of adiposity. Brit J Prev Soc Med 16: 183-188, 1962

6. National Center for Health Statistics: Plan, operation, and response results of a program of childrens' examinations. Public Health Service Publ No 1,000-Series 1, No 5. Oct. 1967

7. National Center for Health Statistics: Plan and operation of a Health Examination Survey of U.S. youths 12-17 years of age. Public Health Service Publ No 1,000-Series 1, No 8. Sept. 1969

8. National Center for Health Statistics: Skinfold thickness of children 6-11 years, U.S.A. DHEW Pub No (HSM) 73-1602, Series 11, No 120, Washington, U.S. Government Printing Office

10. Jelliffe EFP and Jelliffe DB: The arm circumference as a public health index of protein-calorie malnutrition of early childhood. J Tropical Ped 15(4): 179-188, 1969

11. Lauer RM, Connor WE, Leaverton PE, et al.: Coronary heart disease risk factors in school children: The Muscatine Study. J Pediatr 86(5): 697-706. 1975

12. Garn SM, Clark DC, Guire KE: Growth, body composition, and development of obese and lean children. Childhood Obesity Winick M (Ed.) New York: John Wiley \& Sons, Inc., 1975

13. Newens EM, Goldstein H: Height, weight, and the assessment of obesity in children. Brit J Prev Soc Med 26: 33-39, 1972

14. Tanner JM: Growth at Adolescence. Blackwell Scientific Publ, Oxford, 1962 pp 1-27 

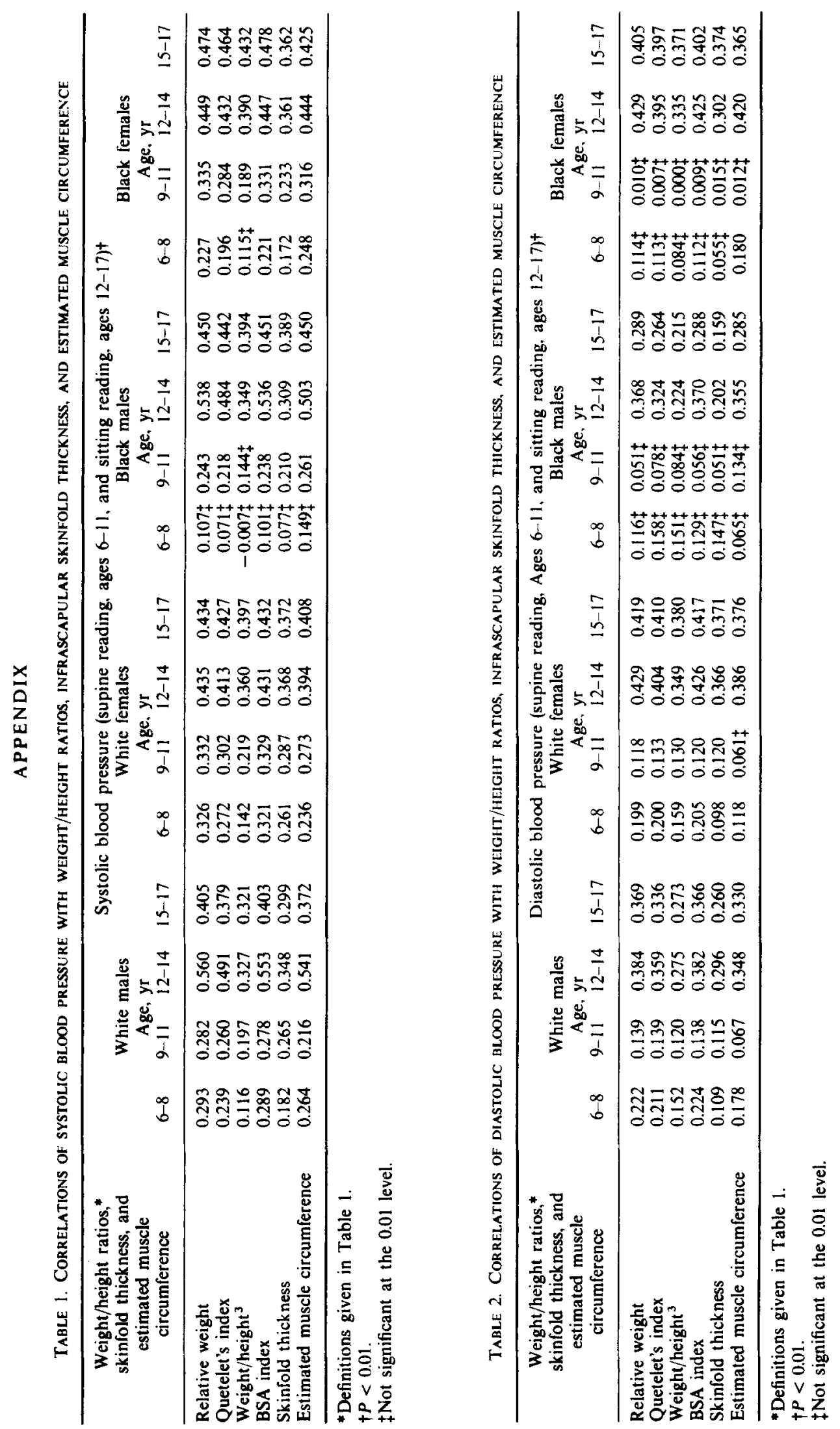


\section{APPENDIX}

TABle 3. CORRELATIONS OF SERUM CHOLESTEROL WITH WEIGHT/HEIGHT RATIOS, INFRASCA PULAR SKINFOLD THICKNESS, AND ESTIMATED MUSCLE CIRCUMFERENCE

\begin{tabular}{|c|c|c|c|c|c|c|c|c|}
\hline \multirow{2}{*}{$\begin{array}{l}\text { Weight/height ratios, } \\
\text { skinfold thickness, } \\
\text { and } \\
\text { estimated muscle } \\
\text { circumference }\end{array}$} & \multicolumn{2}{|c|}{$\begin{array}{c}\text { White males } \\
\text { Age, yr }\end{array}$} & \multicolumn{4}{|c|}{ Serum cholesterol $(\mathrm{mg} / 100 \mathrm{ml}) \dagger$} & \multicolumn{2}{|c|}{$\begin{array}{c}\text { Black females } \\
\text { Age, yr }\end{array}$} \\
\hline & $12-14$ & $15-17$ & $12-14$ & $15-17$ & $12-14$ & $15-17$ & $12-14$ & $15 \cdot 17$ \\
\hline $\mathbf{R}$ & $0.064 \ddagger$ & 0.183 & & 0 & -0 . & $6 \ddagger$ & $0.011 \ddagger$ & $0.064_{+}^{+}$ \\
\hline & & 0.2 & 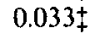 & & -0 & & & $0.105_{+}$ \\
\hline Weight/height ${ }^{3}$ & $0.141^{\top}$ & 0.21 & $0.046_{\ddagger}^{\dagger}$ & 0.1 & $0.054_{+}^{+}$ & 0.1 & $0.049 \ddagger$ & $0.143_{+}^{+}$ \\
\hline BSA index & $-0.053_{+}^{+}$ & 0.187 & $0.021 \ddagger$ & 0.107 & $-0.115 t$ & $0.119 \ddagger$ & $0.014_{+}^{+}$ & 0.074 \\
\hline Skinfold thickness & 0.131 & 0.222 & 0.072 & 0.120 & $0.076 \ddagger$ & $0.068 \ddagger$ & $0.061 \ddagger$ & $0.089+$ \\
\hline Estimated muscle circumference & $-0.046_{+}^{+}$ & 0.150 & $0.029 \ddagger$ & $0.057_{+}^{+}$ & $-0.096+$ & 0.120 & $0.006 \ddagger$ & $0.028 \ddagger$ \\
\hline
\end{tabular}

*Definitions given in Table 1 .

$+P<0.01$.

$\ddagger$ Not significant at the 0.01 level.

Table 4. Correlations OF hematocrit WITH WEIGHT/HEIGHT RATIOS, INFRASCAPULAR SKINFOLD thickNESS. AND ESTIMATED MUSCLE CIRCUMFERENCF

\begin{tabular}{|c|c|c|c|c|c|c|c|c|}
\hline \multirow{3}{*}{$\begin{array}{l}\text { Weight/height ratios, } \\
\text { skinfold thickness. } \\
\text { and } \\
\text { estimated muscle } \\
\text { circumference }\end{array}$} & \multicolumn{8}{|c|}{ Hematocrit $(\mathrm{mg} / 100 \mathrm{ml}) \dagger$} \\
\hline & \multicolumn{2}{|c|}{$\begin{array}{c}\text { White males } \\
\text { Age, yr }\end{array}$} & \multicolumn{2}{|c|}{$\begin{array}{c}\text { White females } \\
\text { Age, yr }\end{array}$} & \multicolumn{2}{|c|}{$\begin{array}{c}\text { Black males } \\
\text { Age, yr }\end{array}$} & \multicolumn{2}{|c|}{$\begin{array}{c}\text { Black females } \\
\text { Age, yr }\end{array}$} \\
\hline & $12-14$ & $15-17$ & $12-14$ & $15-17$ & $12-14$ & $15-17$ & $12-14$ & $15-17$ \\
\hline Relative weight & 0.329 & 0.198 & 0.094 & 0.117 & 0.353 & 0.416 & $0.039 \ddagger$ & $-0.029 \ddagger$ \\
\hline Quetelet's index & 0.232 & 0.173 & 0.083 & 0.098 & 0.270 & 0.314 & $0.056 \pm$ & $-0.029+$ \\
\hline Weight/height ${ }^{3}$ & 0.072 & 0.133 & $0.066 \ddagger$ & 0.075 & $0.123 \ddagger$ & 0.287 & $0.074 \ddagger$ & $-0.026+$ \\
\hline BSA index & 0.316 & 0.197 & 0.091 & 0.111 & 0.344 & 0.424 & $0.040 \ddagger$ & $-0.036 \ddagger$ \\
\hline Skinfold thickness & 0.089 & 0.092 & 0.108 & 0.123 & $0.143+$ & 0.211 & $0.017 \pm$ & $-0.002 \pm$ \\
\hline Estimated muscle circumference & 0.335 & 0.245 & 0.090 & 0.099 & $0.377^{+}$ & 0.478 & $0.062 \pm$ & $0.028 \pm$ \\
\hline
\end{tabular}

*Definitions given in Table 1 .

$+P<0.01$.

$\$$ Not significant at the 0.01 level.

Table 5. Correlations of Serum URic aCid with weight/height Ratios, infrascapular skinfold THICKNESS, AND ESTIMATED MUSCLE CIRCUMFERENCE

\begin{tabular}{|c|c|c|c|c|c|c|c|c|}
\hline \multirow{3}{*}{$\begin{array}{l}\text { Weight/height ratios, } \\
\text { skinfold thickness, } \\
\text { and } \\
\text { estimated muscle } \\
\text { circumference }\end{array}$} & \multicolumn{8}{|c|}{ Serum uric acid $(\mathrm{mg} / 100 \mathrm{ml})$} \\
\hline & \multicolumn{2}{|c|}{$\begin{array}{c}\text { White males } \\
\text { Age. } \mathrm{yr}\end{array}$} & \multicolumn{2}{|c|}{$\begin{array}{c}\text { White females } \\
\text { Age. yr }\end{array}$} & \multicolumn{2}{|c|}{$\begin{array}{c}\text { Black males } \\
\text { Age, yr }\end{array}$} & \multicolumn{2}{|c|}{$\begin{array}{c}\text { Black females } \\
\text { Age. yr }\end{array}$} \\
\hline & $12-14$ & $15-17$ & $12-14$ & $15-17$ & $12-14$ & $15-17$ & $12-14$ & $15-17$ \\
\hline Relative weight & 0.520 & 0.348 & 0.313 & 0.318 & 0.449 & 0.407 & 0.205 & 0.265 \\
\hline Quetelet's index & 0.448 & 0.356 & 0.319 & 0.324 & 0.362 & 0.380 & 0.199 & 0.275 \\
\hline Weight/height ${ }^{3}$ & 0.286 & 0.335 & 0.303 & 0.312 & 0.195 & 0.311 & 0.182 & 0.274 \\
\hline BSA index & 0.513 & 0.349 & 0.315 & 0.318 & 0.439 & 0.401 & 0.200 & 0.265 \\
\hline Skinfold thickness & $0.298 \ddagger$ & 0.312 & 0.301 & 0.300 & 0.234 & 0.340 & 0.196 & 0.310 \\
\hline Estimated muscle circumference & 0.509 & 0.311 & 0.321 & 0.326 & 0.475 & 0.378 & 0.220 & 0.276 \\
\hline
\end{tabular}

* Definitions given in Table 1.

$+P<0.01$.

$\ddagger$ Not significant at the 0.01 level. 